\title{
UMA FLOR NASCEU NO RIO! PAPÉIS DOS ACTANTES NA ENCENAÇÃO NARRATIVA EM CHARGES SOBRE MARIELLE FRANCO
}

\author{
A flower was born in Rio! Roles of actants in the narrative staging in \\ political cartoons about Marielle Franco
}

\author{
Eveline Coelho CARDOSO \\ Rede Municipal de Ensino de Teresópolis/RJ \\ eveline.cardoso@outlook.com \\ Glayci Kelli Reis da S. XAVIER \\ Universidade Federal Fluminense \\ glaycikelli@id.uff.br
}

RESUMO: Dotados de linguagem autônoma e recheados de recursos multimodais, os textos em quadrinhos superam o senso comum que outrora os considerava um tipo de literatura infantil ou menor e ganham cada vez mais diversidade e importância, potencializados pelas mídias digitais contemporâneas. Esse tipo de arte sequencial (EISNER, 2010) têm caráter essencialmente narrativo, por meio do qual se volta para a construção de um universo de representação das ações humanas, oriundo, por sua vez, de uma tensão entre realidade e idealização (CHARAUDEAU, 2009). Como parte desse universo, a charge desenrola, aos olhos do leitor, pequenas narrativas sobre fatos noticiados na mídia jornalística, quase sempre em um único quadrinho, temperando-as com humor e ironia. Assim, a charge funciona como "porta-voz" da sociedade, interpretando-a (TEIXEIRA, 2005). Na pesquisa que ora se apresenta, descreveremos de que maneira a organização narrativa pode servir ao propósito comunicativo das charges, funcionando como um mecanismo importante na produção de seus efeitos de sentido. O corpus analisado são cinco peças de cartunistas brasileiros que tematizam o assassinato da vereadora Marielle Franco e de seu motorista, Anderson Gomes, ocorrido em 14 de março de 2018, no bairro do Estácio, no centro da cidade do Rio de Janeiro. PALAVRAS-CHAVE: Semiolinguística; Histórias em quadrinhos; Narrativa; Charge; Marielle Franco.

\begin{abstract}
Endowed with autonomous language and full of multimodal resources, comic books surpass the common sense that once considered them a kind of children's literature. On the other hand, they gain more and more diversity and importance, enhanced by contemporary
\end{abstract}


digital media. This type of sequential art (EISNER, 2010) has an essentially narrative feature, through which it turns to the construction of a universe of representation of human actions that arises from a tension between reality and idealization (CHARAUDEAU, 2009). As part of this universe, the political cartoon unfolds, under the eyes of the reader, small narratives about facts reported in the news media, most of the time in a single frame, seasoning them with humor and irony. Thus, the political cartoon functions as a "spokesperson" for society, interpreting it (TEIXEIRA, 2005). In this present research, we will describe how the narrative organization can serve the communicative purpose of the political cartoons, functioning as an important mechanism in the production of their effects of meaning. The corpus consists of five works created by Brazilian cartoonists, which discuss the murder of the city councilor Marielle Franco and her driver, Anderson Gomes, fact that took place on March 14, 2018, in the neighborhood of Estácio, in Rio de Janeiro city. KEYWORDS: Semiolinguistics; Comics; Narrative; Political Cartoon; Marielle Franco

\section{PALAVRAS INICIAIS}

\section{Uma flor nasceu na rua! Passem de longe, bondes, ônibus, rio de aço do tráfego. \\ Uma flor ainda desbotada ilude a polícia, rompe o asfalto. Façam completo silêncio, paralisem os negócios, garanto que uma flor nasceu.}

Carlos Drummond de Andrade ${ }^{1}$

Os quadrinhos representam atualmente, sem dúvida, em todo o mundo, um meio de comunicação de massa muito popular: nos quatro cantos do planeta, as publicações de HQ circulam com uma enorme variedade de títulos e tiragens de milhares, até mesmo milhões, de exemplares, adquiridos e consumidos por um público fiel, sempre ávido por novidades (VERGUEIRO, 2012a, p. 7). Além disso, com o desenvolvimento tecnológico, os diversos gêneros em quadrinhos são difundidos amplamente, com uma velocidade e um alcance cada vez maiores.

Conforme Ramos (2010,17), é comum que as histórias em quadrinhos sejam

\footnotetext{
${ }^{1}$ Trecho do poema A flor e a náusea (DRUMMOND, 2003, p.27), publicado originalmente em 1945.
} 
consideradas como uma forma de literatura. No entanto, o autor afirma que essa aproximação nada mais é do que "uma forma de procurar rótulos socialmente aceitos ou academicamente prestigiados", já que os quadrinhos eram vistos historicamente de maneira pejorativa (RAMOS, 2010, p. 17). Em seu ponto de vista, "quadrinhos são quadrinhos", pois estes possuem linguagem autônoma, que usa mecanismos próprios para representar os elementos narrativos, ao integrar elementos verbais e não verbais em sua composição.

Dessa forma, seria possível afirmar que a essência dos quadrinhos é sua narratividade. Conforme aponta Eisner (2010, p. ix), famoso desenhista norte-americano, as histórias em quadrinhos são uma arte sequencial, ou seja, uma "forma artística e literária que lida com a disposição de figuras ou imagens e palavras para narrar uma história ou dramatizar uma ideia". Assim, independente do número de quadros que essa "arte sequencial" possa apresentar, mesmo que seja somente um, as imagens estáticas pressupõem um antes e um depois e, de alguma maneira, "contam uma história". As charges, em especial, têm ancoragem em acontecimentos específicos e, por isso, essa narratividade se torna ainda mais latente, mesmo quando se compõem de um quadro só.

Pode-se afirmar que a função de uma narrativa, portanto, é "contar". De acordo com Charaudeau (2009, p. 154) contar é construir um universo de representação das ações humanas por meio de um imaginário baseado em crenças que dizem respeito ao mundo, ao ser humano e à verdade. Isso se realiza em meio a uma tensão entre o imaginário de uma realidade fragmentada e particular e o de uma idealização homogênea e universal. A narrativa transita entre esses dois imaginários, como se pode ver tanto na Literatura quanto no domínio jornalístico; em ambos os casos, constrói-se um universo contado criando ora efeitos de realidade, ora efeitos de ficção.

$\mathrm{Na}$ pesquisa que ora se apresenta, descreveremos de que maneira a organização narrativa pode servir ao propósito comunicativo das charges, funcionando como um mecanismo importante na produção de seus efeitos de sentido. O corpus da presente investigação são cinco peças de cartunistas brasileiros que tematizam o assassinato de Marielle Franco, vereadora do Rio de Janeiro pelo PSOL-RJ, ocorrido em 14 de março de 2018 no bairro do Estácio, no centro da cidade. Nascida e criada no complexo da Maré, na zona norte da cidade, Marielle era atuante em defesa dos direitos humanos e das causas raciais e contra a violência policial nas favelas do Rio. Na ocasião de sua morte, seu motorista, Anderson Gomes, também foi executado. 


\section{ENTRE NOTÍCIA E OPINIÃO: O GÊNERO CHARGE SOB A PERSPECTI- VA SEMIOLINGUÍSTICA}

Sendo um gênero gráfico de cunho humorístico ou irônico, as charges são marcadas pela ancoragem em um fato específico contemporâneo do chargista, o que, em algumas situações, configura-se como um desafio para os leitores de outra época. Tal aspecto, inclusive, é usado para diferenciar a charge de gêneros como a caricatura, que pretende criticar ou homenagear determinada personalidade conhecida, ou do cartum, cuja temática é mais atemporal e universal.

Recorrendo ao quadro teórico da semiolinguística, podemos pensar as charges como gêneros textuais articulados ao projeto de fala de um enunciador midiático, que representa uma instância de produção em contato com uma instância de recepção. Segundo Charaudeau (2010), o enunciador das mídias se equilibra entre os papéis de pesquisador-fornecedor da informação e o de descritor-comentador na construção de seu discurso, com o duplo objetivo de informar e captar. O chargista, por sua vez, empreende uma relativização desses papéis, pendendo para a captação, tendo em vista que interpreta a realidade de modo a dar destaque aos aspectos que considera mais relevantes e deixa claro um ponto de vista sobre os fatos relatados.

A finalidade do contrato midiático é, portanto, relatar o que ocorre no espaço público, articulando as visadas de informação (fazer-saber) e de captação (fazer-sentir). É na visada informativa que se originam os confrontos da instância midiática com seu dever de credibilidade, pelo qual o enunciador se compromete a mostrar a "verdade" dos fatos. Já a visada de captação prende a instância midiática à necessidade de emocionar o público, expressar afetividade para interessar o receptor. Nesse sentido, o discurso das mídias é produzido na tensão entre efeitos de paixão e racionalidade, navegando "entre esses dois polos [credibilidade e captação] ao sabor de sua ideologia e da natureza dos acontecimentos." (CHARAUDEAU, 2010, p. 93)

Em sua aposta mais atrativa do que informativa, o chargista constrói o mundo e o torna inteligível, baseado em seus saberes de crença e de conhecimento do mundo. Estabelece-se, assim, uma relação de parceria entre as instâncias midiáticas produtora e receptora, na qual ocorre um efeito de "espelho": os parceiros sintonizam-se pelo viés das representações supostamente partilhadas entre si, as quais circulam livremente sendo levadas pelos discursos. É esse o ambiente favorável à chamada opinião pública, que, segundo Charaudeau (2010), é atravessada por uma dramatização na qual se percebem projeções de imagens cristalizadas de sujeitos e acontecimentos capazes de despertar 
efeitos discursivos patêmicos ou humorísticos.

Os efeitos de sentido pretendidos pelo enunciador de textos como as charges podem, assim, ser mapeados na materialidade textual através das escolhas verbais e não verbais empreendidas por ele. Tais escolhas sustentam-se, pois, em representações sociais que também se deixam ver na maneira como são construídos os diversos fatos e tipos sociais que figuram no texto chargístico, a exemplo dos papéis narrativos atribuídos aos personagens representados.

\section{AS HISTÓRIAS CONTADAS POR MEIO DE QUADROS}

Os gêneros em quadrinhos apresentam uma modalidade própria de linguagem, já que dois tipos de signos gráficos se conjugam em sua construção: o visual e o linguístico. Conforme afirma Lins (2008, p. 40), na conjunção entre o visual e o linguístico, “o código visual supre lacunas que, por acaso, possam ser deixadas pelo código linguístico e viceversa e, na análise dos diálogos, a explicação dos fenômenos pode se basear em pistas buscadas em ambos os códigos que compõem os textos".

Vergueiro (2012b, p. 32) aponta que a imagem desenhada (linguagem visual, icônica) é o elemento básico das histórias em quadrinhos, pois ela aparece como uma sequência de quadros que trazem uma mensagem ao leitor, normalmente narrativa. Nas histórias em quadrinhos, a imagem é fixa; o leitor é quem dará dinamismo à história. As palavras, nesse caso, são fragmentos de um sintagma mais geral, juntamente com as imagens, e a unidade da mensagem é feita em um nível superior. No caso dos quadrinhos, especificamente, o diálogo não tem a função de uma simples elucidação, mas faz progredir a ação (narrativa), colocando, na sequência das mensagens, os sentidos que a imagem não traz, enquanto as descrições são confiadas à imagem (BARTHES, 1990, p. 34).

Consideramos aqui, conforme aponta Ramos (2010, p. 20), as histórias em quadrinhos um hipergênero, ou seja, um grande "guarda-chuva" que engloba outros gêneros, cada um com suas peculiaridades, a exemplo das charges, cartuns e tirinhas. No entanto, apesar das diferenças, é possível identificar algumas características das histórias em quadrinhos em geral:

- As histórias em quadrinhos possuem linguagem autônoma e utilizam mecanismos próprios para representar os elementos narrativos;

- nos gêneros em quadrinhos predomina o modo de organização narrativo, mas os outros modos também podem ser encontrados, tanto no texto verbal quanto no visual; 
- a fala e o pensamento das personagens geralmente aparecem em balões, que simulam o discurso direto e a língua oral;

- as histórias normalmente giram em torno de um personagem, que pode ser fixo ou não e que conduz a ação;

- as histórias são repletas de "metáforas visuais".

A menor unidade narrativa de uma história em quadrinhos é a vinheta (ou quadrinho). Vergueiro (2012b, p. 35) define vinheta como "a representação, por meio de uma imagem fixa, de um instante específico ou de uma sequência interligada de instantes, que são essenciais para a compreensão de uma determinada ação ou acontecimento". Desse modo, em um mesmo quadrinho podem estar expressos vários momentos que, vistos em conjunto, dão a ideia de uma sensação específica. Além disso, quanto maior o número de quadros para expressar uma ação, maior a sensação de prolongamento do tempo. Contudo, cabe ressaltar que, conforme já foi mencionado anteriormente, até mesmo uma imagem isolada tem grande potencial de narratividade. No caso específico das charges, fortemente ligadas ao contexto extra-textual, "a imagem traz a história à mente, sustenta-a, ilustra-a" (POSTEMA, 2018, p. 43).

Um elemento característico das narrativas gráficas é a presença de metáforas visuais. Acevedo (1990, p. 146) define a metáfora visual como "uma convenção gráfica que expressa o estado psíquico dos personagens mediante imagens de caráter metafórico" e acrescenta que, por serem uma convenção, as metáforas visuais podem ser consideradas símbolos que, por seu uso frequente, são reconhecíveis pelo leitor. De acordo com Cagnin (2014, p. 100), tal recurso pode ser motivado pela semelhança com o real (por exemplo, o signo icônico de uma poeirinha levantada no chão sugere corrida, uma imagem duplicada sugere tremor ou vibração, entre outros) ou motivado por expressões linguísticas (por exemplo, a imagem de estrelas na cabeça de um personagem vem da expressão "ver estrelas", que pode significar dor causada por uma pancada violenta).

No entanto, pode-se dizer que o elemento mais importante de uma narrativa, seja verbal ou verbo-visual, é o personagem. Os personagens são os "habitantes da ficção" e seu espaço de existência é o texto (BRAIT, 2010, p. 5). Nos quadrinhos, o personagem é tão importante que O’Neill (2005, p. 64) afirma que "personagem é história e história é personagem", pois não se pode ter um sem o outro. Isso se deve ao fato de que "história é ação e ação é o que o personagem faz". Cada personagem tem uma personalidade própria e suas ações na narrativa refletirão isso, como exemplifica o autor: 
Super-homem quer sustentar os valores que ele herdou de seus pais adotivos e se integrar na cultura do mundo que agora é seu lar. Batman quer vingar o assassinato de seus pais. James Bond quer viver uma vida de grandes aventuras temperada com hedonismo e, incidentalmente, servir Sua Majestade. Odisseu quer ir para casa. Frajola quer ter o Piupiu para o almoço (O’NEILL, 2005, p. 67).

Portanto, os papéis que os personagens vão exercer enquanto actantes da narrativa vão ser de grande valor para a construção do sentido do texto. Para entender esses papéis, é preciso analisar a lógica narrativa inerente ao texto. Toda narração pressupõe uma busca, um objetivo, em torno de que a narrativa será arquitetada. Na próxima seção, abordaremos, com mais atenção, a configuração desse processo.

\section{A LÓGICA NARRATIVA E OS PAPÉIS DOS ACTANTES}

O modo de organização narrativo consiste em construir a sucessão das ações de uma história no tempo, com a finalidade de fazer um relato. O sujeito que narra é como uma testemunha que está em contato direto com o vivido (mesmo que seja de uma maneira fictícia), com "a experiência na qual se assiste a como os seres se transformam sob o efeito de seus atos" (CHARAUDEAU, 2009, p. 157).

Segundo Charaudeau (2009, p. 153), “contar” não é simplesmente descrever uma sequência de fatos ou acontecimentos, como definem os dicionários. Contar representa "uma busca constante e infinita"; é uma atividade linguageira cujo desenvolvimento implica uma série de tensões e contradições. Nesse sentido, a narrativa é uma totalidade e corresponde à finalidade do "que é contar" (descreve, ao mesmo tempo, ações e qualificações), enquanto o narrativo (modo de organização) é apenas um de seus componentes, tal qual o descritivo (CHARAUDEAU, 2009, p. 156).

De acordo com a teoria Semiolinguística, o modo de organização narrativo se caracteriza por uma dupla articulação: a realização de uma representação narrativa, isto é, daquilo que faz com que essa história se torne um universo narrado (a organização da encenação narrativa); a construção de uma sucessão de ações segundo uma lógica que vai constituir a trama da história (a organização da lógica narrativa).

Toda narrativa depende da organização da encenação narrativa. A encenação narrativa "constróiouniversonarrado(oucontado) propriamentedito, sobaresponsabilidade de um sujeito narrante que se acha ligado por um contrato de comunicação ao destinatário da narrativa"; esse sujeito age ao mesmo tempo sobre a configuração da organização 
lógico-narrativa e sobre o modo de enunciação do universo narrado (CHARAUDEAU, 2009, p. 158).

Ao falar sobre esse aspecto, Charaudeau (2009, p. 183) explica que "quem conta (uma história) não é quem escreve (um livro) nem quem é (na vida)". Nesse sentido, não se deve confundir o indivíduo, ser psicológico e social, o autor, ser que escreveu, e o narrador, "ser de papel", que conta uma história; da mesma maneira são diferentes o leitor real, a quem é demandado um mínimo de competência de leitura, e o leitor, "ser de papel", destinatário de uma história contada por um narrador.

Com relação à lógica narrativa, Charaudeau baseia-se na semiótica narrativa desenvolvida a partir dos trabalhos de Propp sobre a análise do conto de fadas russo. Segundo o autor, diferentes correntes teóricas foram desenvolvidas a partir desse trabalho, com o objetivo de dar conta do complexo mecanismo da narrativa (CHARAUDEAU, 2009 , p. 152). Cabe ressaltar, contudo, que o ponto de vista escolhido por Charaudeau não é exclusivo de nenhuma teoria, nem pretende ser uma síntese de todas elas. Cada uma tem seu mérito por realçar um aspecto em particular, sem esgotá-lo em sua totalidade.

A organização da lógica narrativa está voltada para o mundo referencial e é resultado da projeção sobre um plano (a história) de algumas das constantes da manifestação semântica da narrativa, ou seja, é uma hipótese de construção do que constitui a trama de uma história. Essa construção se realiza com a ajuda de alguns componentes, cuja configuração é assegurada por certos procedimentos.

Os componentes da lógica narrativa são de três tipos: os actantes, os processos e as sequências. Os actantes desempenham papéis relacionados à ação da qual dependem. Os processos unem os actantes entre si, dando uma orientação funcional à sua ação. As sequências integram processos e actantes numa finalidade narrativa segundo certos princípios de organização (CHARAUDEAU, 2009, p. 160).

O actante participa na esfera da ação e, para conhecer seu papel narrativo (categoria de discurso), é necessário conhecer o contexto que dá ao enunciado (categoria de língua) sua finalidade narrativa. Este, porém, não deve ser confundido com o "personagem" (forma qualificada/não qualificada), visto que um actante, tendo um certo papel narrativo (agressor, benfeitor, aliado, oponente, retribuidor, entre outros), pode ser ocupado por diferentes tipos de personagens, da mesma forma que um mesmo personagem pode desempenhar muitos papéis narrativos e, assim, ocupar o lugar de diferentes actantes, no desenrolar de uma mesma história.

Os processos narrativos podem ser considerados como a semantização das ações (uma ação correlacionada com outras ações, motivada por uma intencionalidade) que 
determinarão a função narrativa; as funções narrativas, por sua vez, estão ligadas aos papéis narrativos dos actantes, que se determinam reciprocamente. Por exemplo, a ação "entrega de um embrulho", dependendo das ações correlacionadas a ela, pode corresponder a um processo de agressão (bomba), de recompensa (presente) ou de enganação (pacote vazio).

Barthes (2011, p. 31), por sua vez, afirma que uma narrativa possui diferentes níveis de significação. Dentre estas, o autor destaca duas grandes classes: as funções e os índices. As funções são as ações que constituem a articulação da narrativa (funções cardinais ou núcleos) ou que simplesmente preenchem o espaço narrativo (catálises). Já os índices remetem não a um ato complementar e consequente, mas a um conceito necessário ao sentido da história. Barthes (2011, p. 33) acrescenta que as funções implicam relatos metonímicos (funcionalidade do fazer); os índices, relatos metafóricos (funcionalidade do ser).

Com relação às sequências, a lógica narrativa é composta por uma sucessão de acontecimentos ligados entre si por uma relação de solidariedade (princípio de coerência); a narrativa produzida, por sua vez, só terá sentido se estiver relacionada a um encadeamento de motivos dirigidos a um fim (princípio de intencionalidade); essas ações ou esses acontecimentos reagrupam-se em sequências ordenadas segundo um princípio de encadeamento; por fim, essa sucessão de acontecimentos coerente e motivada precisa ocorrer em um enquadramento espaço-temporal, segundo um princípio de localização (CHARAUDEAU, 2009, p. 166).

Com relação à produção da charge, é preciso ter em mente que esta se insere no contexto do discurso jornalístico, trazendo à tona, basicamente, um fato em si mesmo, descrito de forma verbo-visual. Contudo, como vimos, a construção desse fato como acontecimento comentado é marcada pela evidência de um ponto de vista do enunciador midiático a respeito do mundo.

Ao observamos o aspecto narrativo da charge, podemos depreender personagens envolvidos em unidades de ação, com um foco mais dinâmico sobre o mundo, apoiado em relações de causa e consequência. Nesse sentido, Charaudeau (1998, p.1) explica que a narrativa é orientada por uma atitude projetiva, que permite ao outro se identificar, e, como um modo secundário, "será apenas uma expansão descritiva necessária para preencher de conteúdo semântico os argumentos da cadeia de raciocínio argumentativa". Em outras palavras, a narrativa encenada na charge por meio de personagens e actantes envolvidos em diferentes ações sustenta a emissão de uma opinião crítica do enunciador sobre os fatos colhidos da realidade extratextual, opinião essa que fica a cargo do leitor decifrar. 


\section{UMA FLOR (RE)NASCEU NO ASFALTO: PAPÉIS NARRATIVOS EM CHARGES SOBRE MARIELLE FRANCO}

As charges são capazes de transmitir múltiplas informações de maneira condensada (ROMUALDO, 2000, p. 17). Desse modo, apesar de aparentemente serem de fácil leitura, todos os mínimos detalhes contribuem para a construção de seu significado. $\mathrm{O}$ pesquisador Luiz Guilherme Teixeira (2005, p. 78) defende que a charge se apoia em um "não senso" que, comparado à realidade, dá sentido ao seu conteúdo não pela falta, mas por um excesso, que significa que nela há sentidos demais. Com efeito, em um texto tão sintético, cada pormenor tem o seu papel na construção dessa realidade verbo-visual potencialmente crítica e polissêmica.

Teixeira afirma que, por sua ligação com os fatos reais noticiados no jornal, a charge tempera a monotonia e a severidade do texto verbal com um discurso mais permissivo, que "diz o que o verbo não pode, não deve, não ousa expressar" (TEIXEIRA, 2005, p. 13). Nesse sentido, descreve a importância do gênero como uma espécie de porta-voz da sociedade, que fornece uma interpretação subjetiva da notícia, "transformando o fato numa consciência sobre ele" (TEIXEIRA, 2005, p. 79).

As peças que nos servem nesse estudo tematizam um acontecimento bastante replicado na mídia jornalística impressa, televisiva e nas redes sociais: o assassinato da vereadora Marielle Franco no Rio de Janeiro, em 14 de março de 2018. Marielle, 37 anos, era originária do Complexo da Maré, favela da zona norte da cidade, e foi a quinta vereadora mais votada nas últimas eleições, em que se lançou pelo Partido Socialismo e Liberdade. Sempre defendeu as causas raciais, as pautas feministas e de outras minorias sociais. Seu assassinato coincide com um período de intervenção federal no Rio de Janeiro, durante o qual atuou como relatora de uma comissão que acompanharia o processo. Sob tal responsabilidade, Marielle já havia tecido críticas às ações da Polícia Militar do Rio, classificando uma de suas divisões como "esquadrão da morte"2.

A Figura 1, primeiro exemplo que servirá a nossa análise, foi criada pelo cartunista piauiense Izanio e foi publicado em 15 de março de 2018: 
Figura 1: Charge de Izanio

\section{MARIELLE FRANCO}

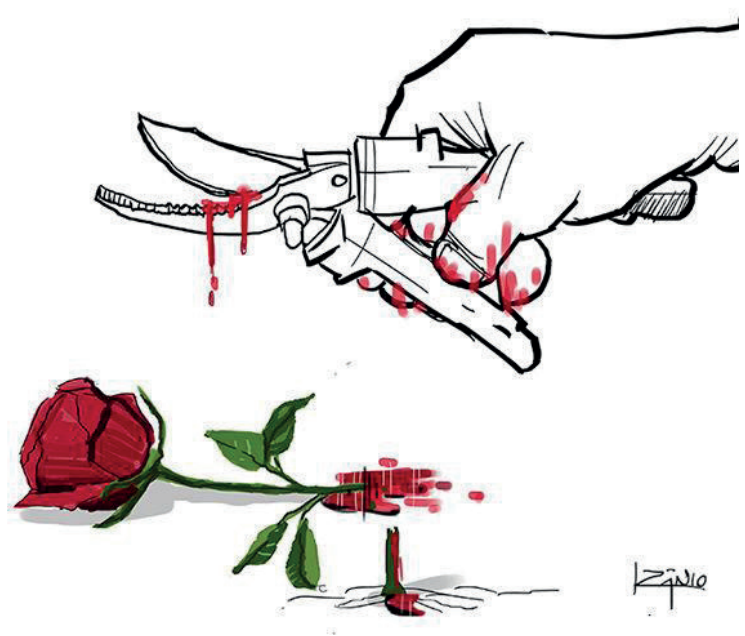

Fonte: $<$ https://www.oitomeia.com.br/colunas/charge-do-izanio/2018/03/15/marielle-franco/>. Acesso em:10 mai. 2019.

Visualmente, a charge se estrutura em torno de uma cena sem um fundo definido e sem uma moldura, em que se destacam, em primeiro plano, uma rosa cortada e uma mão portando um alicate, ambos contendo o sangue oriundo do corte da flor. Não há sequer uma moldura delimitando a imagem, o que projeta uma sensação de atemporalidade. A construção cromática efetiva um contraste entre os contornos e preenchimentos da mão em preto e branco e da flor, coloridos. Do ponto de vista topológico, a mão permanece sobre a flor cortada.

Na parte verbal da imagem, destaca-se a legenda "Marielle Franco", que situa a charge em relação à ocorrência do assassinato da vereadora, ao mesmo tempo em que empreende uma qualificação da flor, que representaria a mesma. Izanio descreve, pois, o assassinato de Marielle Franco como o corte de uma rosa.

O movimento da mão, a disposição do alicate e o posicionamento da rosa no chão, próxima ao caule, sugerem a ação de cortar, que teria acabado de acontecer aos olhos do leitor. O movimento do sangue escorrendo da rosa no chão e no caule podado, bem como das mãos e do alicate, denotam uma continuidade do sangramento no tempo, não obstante a charge ser construída por uma única imagem fixa. 
Sob a perspectiva narrativa, precisamos considerar que essas personagens não estão colocadas na imagem de forma meramente descritiva ou estática, mas há uma relação actancial entre elas, sob certa lógica de coerência. Quanto aos papéis narrativos, notemos que não há um agente identificado responsável pela ação. Sua presença é metonimicamente marcada apenas pela mão de um agressor, que comete um malefício de maneira voluntária e direta contra a flor. Já esta é a actante que sofre a ação como vítima, afetada negativamente pela ação da mão.

O contraste cromático favorece as qualificações negativas/positivas, exibindo uma relação inversa entre vida e morte: a rosa, que representa Marielle assassinada, é colorida com cores fortes, especialmente o vermelho. Segundo Chevalier e Gheerbrant (2008, p. 944), o vermelho simboliza universalmente o princípio de vida, matricial, uterino. É marcado, ainda, por uma ambiguidade, que ora seduz, encoraja, provoca; ora alerta, incita à vigilância, inquieta. Já a mão, que representa o actante agressor vivo, não tem cor e é salpicada pelo sangue - a vida - que emana da rosa.

Assim, do conjunto da imagem, pode-se depreender a narrativa do assassinato de Marielle como sendo fruto da ação fria de um agente não identificado, que, à semelhança do corte de uma flor, sobrepõe-se e ceifa a vida da vereadora de forma deliberada e cruel. Como uma rosa vermelha, a representação de Marielle comporta as ambiguidades do simbolismo da cor: uma figura política que encoraja e provoca as pessoas contra as irregularidades das ações da polícia e de outros grupos públicos, bem como irrita e incomoda essas classes, que talvez há tempo desejassem o seu fim.

A Figura 2, criada pelo cartunista baiano Gilmar, foi publicado no site Humor Político em 15 de março de 2018: 
Figura 2: Charge de Gilmar

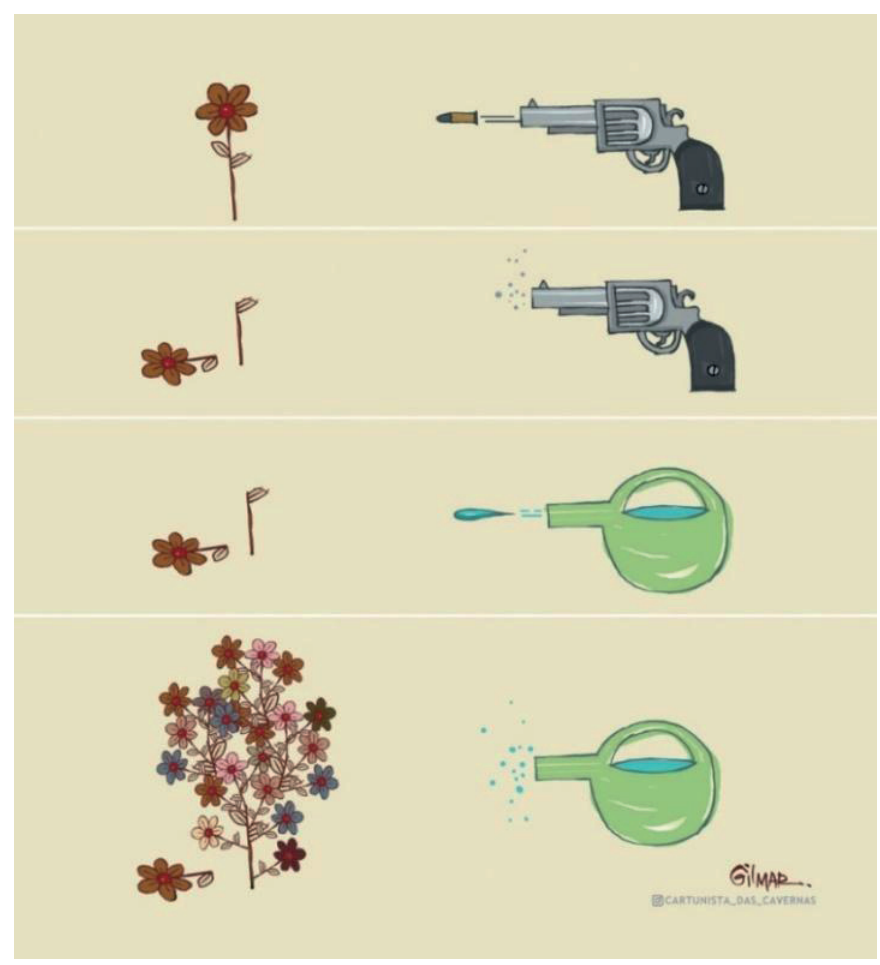

Fonte: <https://www.humorpolitico.com.br/gilmar/marielle-franco/>. Acesso em: 26 abr. 2019.

Na representação de Gilmar, novamente temos um cenário com fundo indefinido e, em primeiro plano, destacam-se as figuras que compõem a narrativa num mesmo plano topológico. Dessa vez, explora-se mais a temporalidade em virtude das várias vinhetas que simulam a evolução da ação. Como na representação de Izanio, Gilmar também recorre à comparação de Marielle com uma flor, dessa vez golpeada pela mesma arma que a executou na realidade: uma arma de fogo.

A ação, dessa vez, subdivide-se em dois momentos contrastantes que simulam o disparo de um tiro: no primeiro e no segundo quadrinho, desenrola-se o disparo de uma bala proveniente de um revólver contra a flor. No segundo e no terceiro quadro, a flor cortada pela ação anterior é atingida pelo tiro de uma gota de água disparado por um regador, que faz com que, de seu caule, brotem dezenas de outras flores. Note-se que, além da progressão dos quadros, metáforas visuais simulam o movimento da bala e da gota em direção à flor, bem como da difusão dos disparos no ar, contribuindo para o efeito de continuidade do tempo. 
A estrutura em quadros põe em evidência três tipos de actantes: um agressor que efetua o disparo da arma; uma vítima, que é a flor cortada pelo tiro; e um benfeitor, que promove o renascimento da flor regando-a. Tais actantes são retratados metonimicamente, no caso do agressor e do benfeitor, que são representados pelos instrumentos que promovem sua ação na narrativa; e metaforicamente, no caso de Marielle, que é comparada a uma flor.

Vale ressaltar o contraste da arma, tão agressiva, para atacar à delicada florMarielle. Em uma segunda etapa, simulando o mesmo gesto da ação negativa, o que parece ser um novo actante benfeitor rega a flor, levando-a a multiplicar-se, em referência às manifestações que ocorreram como protesto pela morte da vereadora. $\mathrm{O}$ conjunto da cena contrasta, então, o matar, que "poda" a flor, e o regar, que a leva ao reflorescimento e à multiplicação.

Representação semelhante à de Gilmar aparece nesta peça de Quinho (Figura 3), publicada no site de notícias Brasil 247, em 16 de março de 2018.

Figura 3: Charge de Quinho

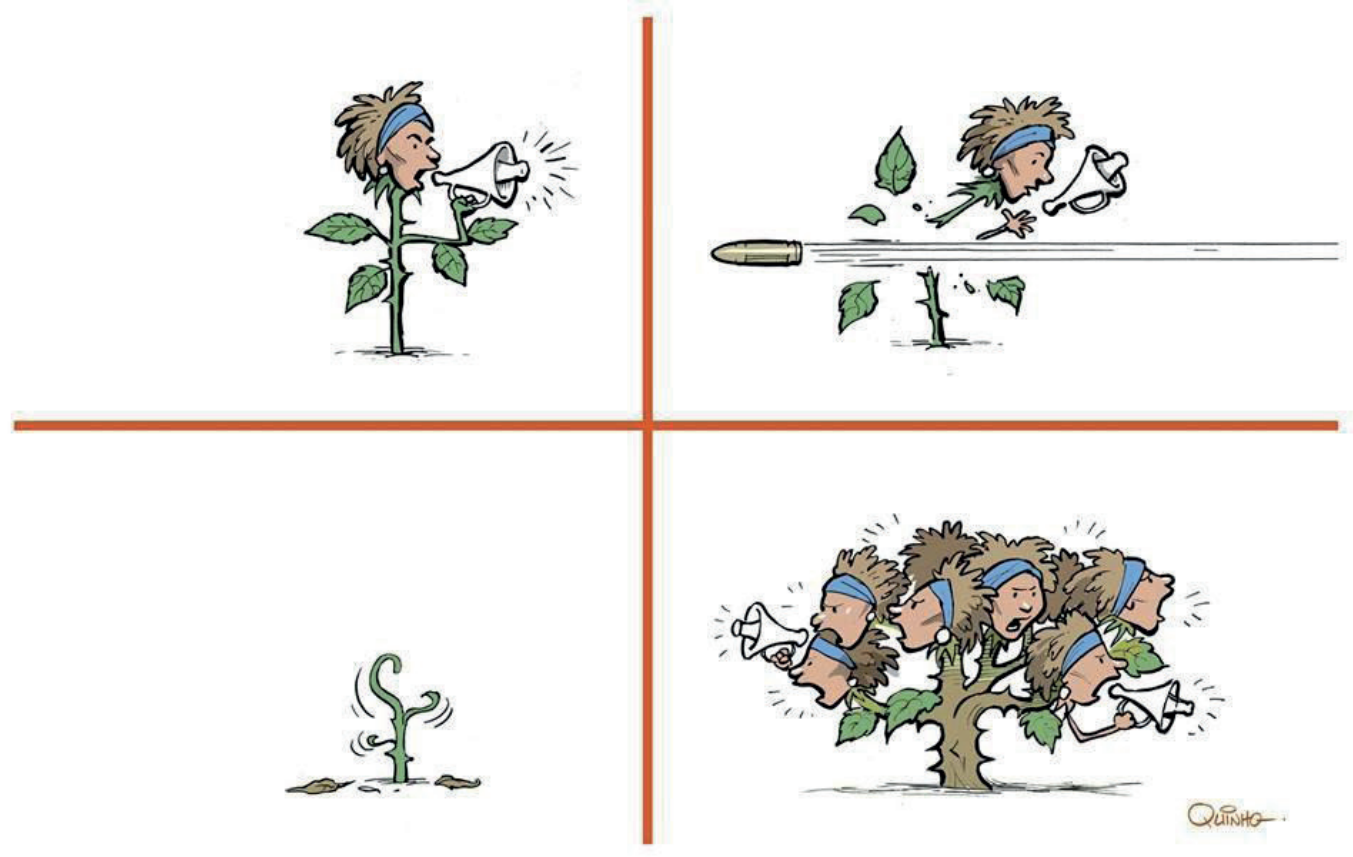

Fonte: $<$ https://www.brasil247.com/pt/247/brasil/347092/\%E2\%80\%9CQuiseram-te-enterrarmas-n\%C3\%A3o-sabiam-que-eras-semente\%E2\%80\%9D.htm>. Acesso em: 24 abr. 2019. 
A perspectiva de Quinho também explora o desenrolar da ação em vários quadros, por meio do qual o chargista também tematiza o assassinato de Marielle associando-o com o corte de uma flor. Diferente das Figuras 1 e 2, aqui a flor é uma caricatura de Marielle personificada, que dá vida a essa figura política, simulando, inclusive, sua militância, por meio da presença do megafone. A evolução da sequência novamente caminha do matar ao reviver de forma mais intensa e multiplicada.

A actante vítima agora é uma personagem ativa, como Marielle, o que pode sinalizar a causa de incomodar seu agressor, que atuaria no sentido de retribuir sua ação de protesto. Vale notar a expressão facial que denota o envolvimento dedicado da vereadora com seu papel social e as linhas de movimento saindo do megafone, que ampliam a sensação de temporalidade e vivacidade de sua ação de protestar. Já a figura do actante agressor sequer aparece na charge, sendo pressuposta apenas pelo projétil disparado, o que, mais uma vez, associa-se à indefinição da autoria do crime. O tiro é certeiro e incisivo, remetendo à maneira como a ação real ocorreu.

Como na representação de Gilmar, tão logo é cortado, o broto da flor-Marielle revive e logo se fortalece por si mesma, ampliando-se em muitas flores que replicam sua ação de protestar como actantes. A interpretação do conjunto lembra a conhecida frase atribuída a Friedrich Nietzsche "o que não nos mata nos torna mais fortes", em uma tentativa de negar a morte da vereadora e enfatizar como sua figura é simbólica para a continuidade da luta pelas causas sociais. Na perspectiva de Quinho, a ação contrária a Marielle, mais uma vez, é qualificada negativamente, ao passo que sua luta e resistência recebem qualificação positiva

A Figura 4, de autoria do paulista Gilberto Maringoni, foi publicada no jornal digital Diário do Centro do Mundo, em 25 de março de 2018: 
Figura 4: Charge de Maringoni

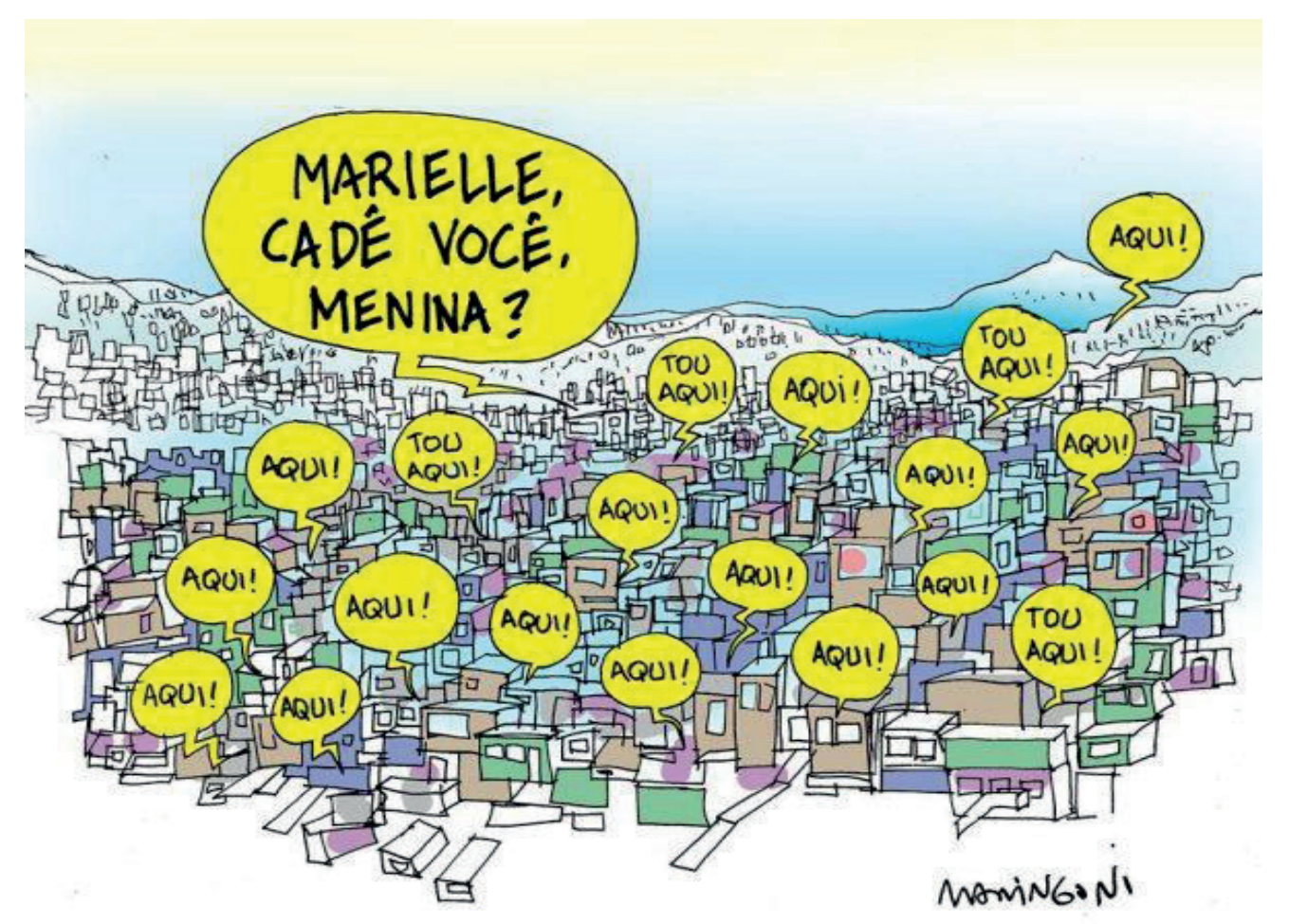

Fonte: $<$ https://www.diariodocentrodomundo.com.br/a-homenagem-de-gilberto-maringoni-paramarielle/>. Acesso em: 26 abr. 2019.

O cenário explorado por Maringoni é o contexto da origem e da atuação de Marielle: as comunidades cariocas. Isso pode se percebido pela presença de muitas casas próximas umas às outras e o desenho do morro ao fundo. Metaforicamente, como um índice, a comunidade é representada com cores frias, denotando a tristeza dos moradores por causa do assassinato de uma pessoa que tanto por eles lutou.

No entanto, a presença desses mesmos moradores não aparece visualmente. Podese dizer que a charge de Maringoni explora a ideia de uma ausência que se converte em presença potencializada, sinalizando que o objetivo dos assassinos - calar uma voz política opositora - foi frustrado. A ausência é enfatizada no enunciado verbal, que pergunta por Marielle, o qual é respondido em muitos balões que emanam de muitas casas, representando as vozes que ocupam o lugar da vereadora após sua morte.

Os balões são postos em destaque, na cor amarela, uma cor quente, em contraste com as cores frias do local. A escolha do amarelo pode tanto denotar atenção quanto 
vitalidade, movimento, demonstrando que as pessoas, apesar de tristes, reagiram ao acontecido e ganharam força para lutar, em vez de ficarem chorando seu luto.

Com relação aos papéis narrativos, no caso dessa charge, os agressores estão implícitos pela situação/notícia em que a charge está ancorada: os assassinos de Marielle, que causaram a tristeza e o luto para a comunidade nesse contexto. A pessoa que tem a fala principal (“Marielle, cadê você, menina?") é quem inicia a ação na breve narrativa, como um actante-vítima, em resposta aos agressores. As pessoas que respondem ao chamado desse actante-vítima configuram como seus aliados, num movimento de solidariedade, fortalecendo sua luta e juntando-se a ele.

A última peça a ser analisada - Figura 5 - é de autoria do chargista carioca Vini Oliveira, publicada em seu site pessoal, em 15 de março de 2018:

Figura 5: Charge de Vini

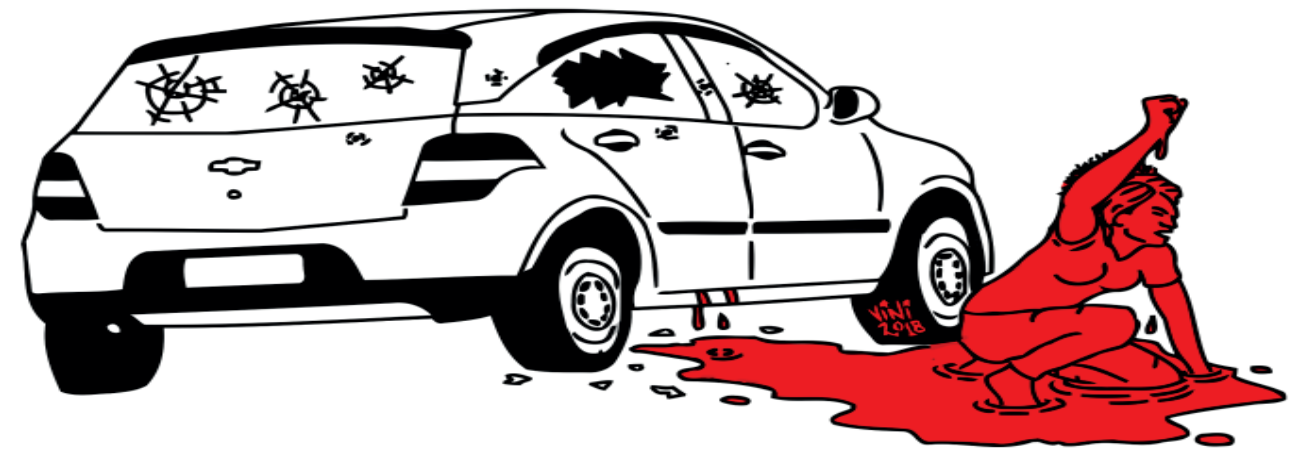

Fonte: https://vinioliveiracharges.wordpress.com/2018/03/15/dor-se-converte-em-luta-mariellefranco-presente/. Acesso em: 10 mai. 2019.

Na Figura 5, Vini reconstrói visualmente a cena do crime em que Marielle foi assassinada. O carro é do mesmo modelo em que ela estava naquela noite e é possível ver os disparos nos vidros e na lataria do veículo. Uma grande quantidade de sangue escorre, vinda de dentro do carro, e forma uma poça no chão. Aqui, o actante agressor não aparece. Ele está implícito pelos traços que reconstroem o assassinato.

Como na representação da Figura 1, o contraste cromático é bastante evidente, pondo em destaque a figura da vereadora na cor vermelha. A ênfase é, portanto, dada à figura de Marielle, que, contrariamente à notícia de sua morte, surge como actante do 
meio do sangue, em um gesto de luta, com o punho direito erguido, projetando-se para cima. O punho cerrado é hoje um símbolo de resistência das minorias. Ela passa, então, de vítima a actante, pois reage contra o seu agressor, ao que parece, dando uma resposta contrária à tentativa de silenciamento.

É possível depreender na representação da vereadora qualificações positivas de coragem, enfrentamento e resistência. Além disso, o vermelho torna-se simbólico duplamente, pois ainda simboliza a própria esquerda, linha política de Marielle. Seu punho erguido pode ser compreendido também como uma convocação de todos para a luta, pois ela levanta da poça, renascendo das cinzas como uma fênix, como a flor simbolizada nas Figuras 2 e 3, a flor que renasce no asfalto do Rio de Janeiro.

\section{ALGUMAS CONSIDERAÇÕES}

De acordo com O’Neill (2005, p. 10), os quadrinhos não são simplesmente a junção de palavras e imagens impressas em uma mesma página; para ser uma história em quadrinhos, tais palavras e imagens devem trabalhar juntas para construir uma informação, ou contar uma história. No caso dos gêneros em quadrinhos, portanto, palavra e imagem exercem, juntas, as funções descritiva e narrativa. Por esse motivo, é preciso considerar tanto a parcela verbal quanto a não verbal em sua análise, já que ambas as formas textuais contribuirão para a construção do sentido.

Ao contar uma história, a construção dalógica narrativa se realiza com a ajuda de alguns componentes. Os actantes participam da ação e desempenham papéis narrativos. Os processos constituem a semantização das ações que determinarão a função narrativa. As sequências integram processos e actantes numa finalidade narrativa, em uma sucessão de acontecimentos ligados entre si, com um princípio de coerência, relacionados a um encadeamento de motivos dirigidos a um fim, em sequências ordenadas, em um enquadramento espaço-temporal. Neste artigo, foram abordadas cinco charges que mostram perspectivas ora semelhantes, ora diferentes, de um mesmo tema. Com isso, foi possível observar várias formas de se representar um mesmo papel narrativo na construção da lógica interna, com o objetivo de contar uma pequena história, colocando em relevo os elementos que emanam do conhecimento prévio do leitor.

É importante ainda lembrar que a narração, ao transitar entre os efeitos de realidade e ficção, construindo, assim, uma visão ora objetiva, ora subjetiva de mundo, muitas vezes refletirá as representações socioculturais que circulam na sociedade na qual o sujeito falante está inserido. Conforme aponta Charaudeau (2009, p. 154), contar representa uma 
busca constante e infinita da resposta para perguntas fundamentais que o homem se faz: “Quem somos? qual é a nossa origem? qual é nosso destino?”, ou seja, “qual é a verdade de nosso ser?"; e como esta não se deixa descobrir, o homem, através de seu imaginário, produz narrativas que, falando de fatos e gestos dos seres humanos, liberam parcelas dessa verdade.

Como produto do contrato comunicativo midiático, a matéria-prima da charge são os acontecimentos cotidianos, como vimos. Seu enunciador extrai deles os aspectos que considera mais relevantes e os organiza em seu discurso, promovendo novas relações de sentido que emanam do encontro verbo-visual. Trata-se de uma notícia temperada por uma opinião, que, para Luiz Guilherme Teixeira $(2005$, p.11) se propõe não a registrar o real, mas a significá-lo.

Nas charges em tela, pela análise dos componentes da narrativa, observou-se que Marielle passa de actante paciente (que sofre a ação), no papel de vítima, a agente, reagindo à tentativa de silenciamento de sua voz. Ela faz isso nos textos mesmo que de maneira involuntária, como benfeitora, pois "abriu" os olhos da população e incentivou os jovens a lutarem por seus direitos. Nesse sentido, recebe as qualificações de forte, honesta, lutadora. Os agressores, não identificados, são seus oponentes, e, por vê-la como uma ameaça, têm como ação a "eliminação" dessa ameaça, tentando "neutralizar" a luta. Entretanto, o efeito é contrário, uma vez que, tendo Marielle se tornado seu símbolo, replicou-se em muitas "Marielles" nascidas de sua semente.

Enfim, após a análise do material, é possível afirmar que, apesar de predominar a narração, as charges podem ser percebidas como um gênero de forte importância argumentativa. Conforme aponta Agostinho (1993, p. 229), no universo da comunicação, a charge não pretende apenas distrair o leitor, mas, além disso, "alertar, denunciar, coibir e levar à reflexão". Pelas características apresentadas, tal gênero textual constitui um objeto de estudo bastante relevante se o professor levar os alunos a analisarem os elementos verbais e não verbais, além dos pressupostos e subentendidos que emergem da relação entre esses dois elementos, favorecendo, assim, a formação de cidadãos mais críticos na sociedade em que vivem. 


\section{REFERÊNCIAS:}

ACEVEDO, J. Como fazer histórias em quadrinhos. Tradução de Sílvio Neves Ferreira. São Paulo: Global, 1990.

ANDRADE, C. D. A rosa do povo. 27 ed. Rio de Janeiro: Record, 2003.

ANDRADE, C. D. Antologia Poética. 12. ed. Rio de Janeiro: José Olympio, 1978. p. 14-16.

AgOStinhO, A. T. A charge. Escola de Comunicações e Artes, Universidade de São Paulo. São Paulo: USP, 1993. 330 f. Tese (Doutorado).

BARTHES, R. O óbvio e o obtuso: ensaios críticos III. Trad. Lea Novaes. Rio de Janeiro: Nova fronteira, 1990.

BARTHES, R. Introdução à análise estrutural da narrativa. In: BARTHES, Roland [et. al.] Análise estrutural da narrativa. Tradução de Maria Zélia Barbosa Pinto. 7. ed. Petrópolis: Vozes, 2011.

BRAIT, B. A personagem. 8. ed. $3^{\text {a }}$ reimp. São Paulo: Ática, 2010.

CAGNIN, A. L. Os quadrinhos: linguagem e semiótica: um estudo abrangente da arte sequencial. 1 ed. São Paulo: Criativo, 2014.

CHARAUDEAU, P. Linguagem e discurso: modos de organização. $1^{\mathrm{a}}$ ed., $1^{\mathrm{a}}$ reimpressão. São Paulo: Contexto, 2009.

CHARAUDEAU, P. Discurso das Mídias. Trad. de Angela M. S. Corrêa. 1 ed., $1^{\mathrm{a}}$ reimpressão. São Paulo: Contexto, 2010.

CHEVALIER, J.; GHEERBRANT, A. Dicionário de símbolos: (Mitos, sonhos, costumes, formas, figuras, cores, números. Colab. André Barbault (et. al.), Trad. Vera da Costa e Silva (et. al.). 22 ed. Rio de Janeiro: José Olympio, 2008.

EISNER, W. Quadrinhos e Arte Sequencial. 4ed. São Paulo: Martins Fontes, 2010.

LINS, M. P. P. O tópico discursivo em textos de quadrinhos. Vitória: EDUFES, 2008.

O’NEILL, D. Guia Oficial DC Comics: Roteiros. São Paulo: Opera Graphica, 2005.

POSTEMA, B. Estrutura narrativa nos quadrinhos: construindo sentido a partir de fragmentos. São Paulo: Peirópolis, 2018. 
RAMOS, P. A leitura dos quadrinhos. São Paulo: Contexto, 2010.

ROMUALDO, E. C. Charge jornalística: intertextualidade e polifonia: um estudo de charges da Folha de S. Paulo. Maringá: Eduem, 2000.

TEIXEIRA, L. G. S. Sentidos do humor, trapaças da razão: a charge. Rio de Janeiro: Fundação Casa de Rui Barbosa, 2005.

VERGUEIRO, W. Uso das HQs no ensino. In: RAMA, A.; VEGUEIRO, W. (orgs.). Como usar as histórias em quadrinhos na sala de aula. 4 ed. São Paulo: Contexto, 2012a. p. 7-29.

VERGUEIRO, W. A linguagem dos quadrinhos: uma "alfabetização" necessária. In: RAMA, A.; VEGUEIRO, W. (orgs.). Como usar as histórias em quadrinhos na sala de aula. 4 ed. São Paulo: Contexto, 2012b. p. 31-64. 